\title{
BRIDGING GENDER AND CASTE BASED GAP IN EDUCATION: LESSONS FROM A PILOT IN RAJASTHAN, INDIA
}

\author{
Saigal $\mathrm{N}^{1^{*}}$ and Shrivastava $\mathrm{S}^{2}$ \\ ${ }^{I}$ Associate Director, IPE Global (New Delhi), India \\ ${ }^{2}$ Research and Policy Manager, IPE Global (New Delhi), India
}

\begin{abstract}
Girls in Rajasthan face several barriers in accessing education that range from physical (distance to schools), infrastructure, discriminative social norms, and a lack of incentive for families to send girls to schools beyond a certain age. COVID-19 has worsened the situation with school closures and several girls engaged in household chores. It becomes more challenging for girls who are at the intersections of caste, class, and poverty. Data shows that gender differentials in access to education are stark at secondary and senior secondary levels. Caste-based differentials are also observed with higher dropouts among girls from Scheduled Caste (SC) and Scheduled Tribe (ST) communities. IPE Global, in collaboration with AMIED, NGO based in Rajasthan, piloted a leadership model to bridge the gap in access to education for girls from SC and ST communities. This was based on the pedagogy of Leadership, Organising and Action (LOA) and a snowflake leadership structure was built and led by girls from these communities. This paper used qualitative surveys with a cohort of girls to study the role of this leadership model in supporting girls from marginalised communities in accessing education and bridging inequalities, and explores the potential for scaling it up across State of Rajasthan and other States. Structured, open-ended questionnaires were used to conduct Focus Group Discussions with girls who are a part of the movement and results were analysed in context of seven themes linked to the study objectives. Preliminary results indicate success of LOA pedagogy in promoting equitable access. Girls' leadership collective commenced with 10 girls, is now an alliance of more than 1200 girls within three months. The girl leaders have become a social and political force in their district, with enhanced agency and voice. It builds a strong case for replicating and scaling up this leadership model in other districts of Rajasthan. Lessons from the pilot in Karauli will be critical in informing its replication and adaptation to other districts.
\end{abstract}

Keywords: girls' education, equitable access, Leadership Organising and Action (LOA), marginalised communities, caste, gender

\section{Introduction}

Rajasthan, located in the western part of India, is the largest state in the country in terms of geographical area. The state is largely rural (over $75 \%$ of its population resides in rural areas) and has a significant proportion of population belonging to disadvantaged communities - the Scheduled Castes (SCs) and Scheduled Tribes (STs) $-17.8 \%$ and $13.5 \%$ respectively, against a national average of $16.6 \%$ and $8.6 \%$ respectively (Registrar General of India, 2011). Rajasthan has a long way to go in providing equal opportunities and ensuring equitable access to education for girls, especially those 
from disadvantaged communities (Nagpal, n.d.; Jejeebhoy and Acharya, 2014; Choudhary, 2019). The significant, persisting gender and caste disparities in access to education at all levels, increase at higher levels, with declining participation of girls especially belonging to disadvantaged groups (as discussed in detailed subsequently).

\section{Gender and Caste differentials in Education in Rajasthan}

As per the fourth round of the National Family Health Survey (NFHS-4), only 56.5\% women in Rajasthan were literate, compared to $85.4 \%$ males (IIPS, 2017). In fact, Rajasthan has the lowest literacy rates for women among all states in India (NSSO, 2018). A meagre 25\% females in age group 15-49 years have completed 10 or more years of schooling, implying that over three-fourth females in the state have not completed even secondary level of education. Moreover, $41 \%$ women in Rajasthan have never been to school, compared to only $13 \%$ of men (IIPS, 2017).

The data by Ministry of Human Resource Development (MHRD, 2018) shows that the gender differentials in accessing education become starker with the progression in levels of education. In 2015-16, gender differential in Gross Enrolment Ratio (GER) at secondary level in Rajasthan was close to 11 percentage points, with GER being $81 \%$ for boys and $70 \%$ for girls. This increased to a differential of 15 percentage points at higher secondary level, with GER of boys being $66 \%$ and for girls being 52\% (MHRD, 2018). As per the NFHS-4, in Rajasthan the gender disparity in school attendance also increases in age group 15-17 (63\% of girls compared with $78 \%$ of boys), compared to age group 6-14 years (87\% of girls compared with $93 \%$ of boys) (IIPS, 2017).

Access to education among girls from disadvantaged groups such as the SCs and the STs is lower, and the gender differentials are equally stark. This makes the girls from these communities doubly disadvantaged. Data shows that in 2015-16, the GER for boys from All Groups was 66\%, for girls from All Groups was 52\% (MHRD, 2018) (see figure 1). The GER for the SC girls and ST girls was lower at $46 \%$ and $49 \%$ respectively. The dropout rates among the girls from SC and ST communities are much higher compared to All groups taken together. On an average, 24.4\% ST girls and 19.1\% SC girls, dropout at secondary education level, compared to 16.9\% girls from All groups (MHRD, 2018). Analysis by authors based on data on enrolment from Ministry of Human Resource Development (NUEPA, various years) shows that around 54\% SC and 59\% ST girls enrolled in Class 1, drop-out before reaching Class 10, compared to $42 \%$ General category girls.

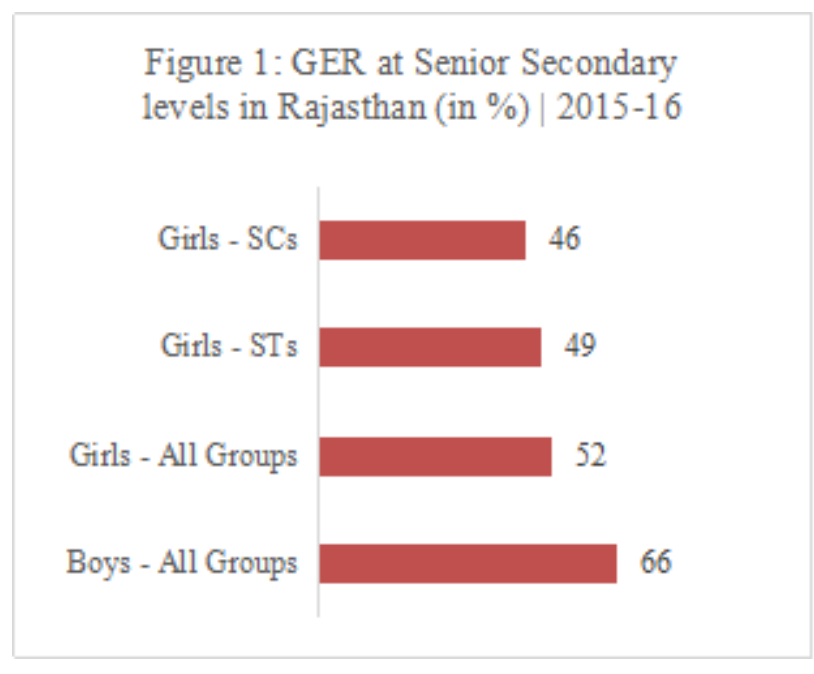




\section{Challenges faced by girls in accessing secondary education exacerbated by COVID-19}

A range of gender and caste related factors combine to restrict access to secondary education for girls in Rajasthan, especially for girls from SCs and STs, who face additional challenges. Some of these include:

\section{Physical barriers:}

Long and often unsafe distance to schools: Most girls in rural areas do not have access to safe transport facilities for daily commute to school, and the distance to secondary schools is long, often unsafe and through difficult terrain (such as agricultural fields, kutcha road etc.) (Jejeebhoy and Acharya, 2014). Reports of girls facing harassment on the way to school, especially when crops are fully grown in fields reducing open space and public visibility, is common.

Lack of adequate infrastructure within schools such as lack of separate, functional toilet for girls is a major hindrance. Disposal of sanitary napkins in school poses an additional challenge in absence of proper garbage disposal facilities. The girls find it difficult to attend school during their menses, leading to lower attendance rates, loss of learning and inability to keep up with the learning levels in school (Bhagavatheeswarana et al., 2016).

\section{Social Barriers:}

Burden of domestic responsibilities and less value attached to a girl's education by family and society: Primary role of a girl still considered to be marriage and management of her family, and household chores (Choudhary, 2019). In Rajasthan, 45\% females who enrolled were not attending schools, engagement in domestic activities was the main reason (NSSO, 2017-18). During the COVID-19 lockdown, studies reported an increase in burden of domestic responsibilities of girls (Development Solutions and IDS Jaipur, 2020).

Child marriage: is a common practice in Rajasthan where one in every three girls is married before reaching 18 years of age (IIPS, 2017), leading to them dropping out from schools. With the lockdown, Rajasthan reported a surge in incidence of child marriages. Uncertainty over girls' future education, families' own financial constraints and a marriage costing less amid lockdown with restricted guests were seen as key reasons for this (Ellis-Petersen, 2020; Parth 2021).

Caste-based discrimination in schools by teachers and peers: The SC and the ST students report facing verbal and physical abuse at hands of both students and teachers in school (Bhagavatheeswarana et al., 2016). Calling someone by their caste, making them sit separately, not using same utensils or water taps, having to wait in ques where precedence is given to children from so-called "higher castes" is fairly common (Nambissan, 2009).

Girls from SC and ST communities are mostly first-generation learners who find it difficult to keep up with the pace at school, find little help at home in studies as their parents are illiterate or have limited education, and often have to work outside school hours in household chores or economic activities to supplement household income (Awasthy and Khimani, 2015; Ghosh, 2014). 
III. Economic barriers:

Economic barriers at household level, exacerbated by the fact that secondary education in not free: The direct costs (e.g., school fees where they exist, uniforms, transportation) and opportunity costs (e.g., time could have spent working or helping family) associated with girls' education, compounded by lesser value attached to girls' education, make families reluctant to spend on girls' education, acting as major hindrance in their access to education (Bhagavatheeswarana et al., 2016).

\section{Impact of COVID:}

The COVID-19 pandemic and the subsequent lockdown further worsened the situation for these girls, whose access to education has been adversely impacted and taken a backseat in view of the larger health and survival concerns (Development Solutions and IDS Jaipur, 2020). The study by Development Solutions and IDS Jaipur (2020) found that several families had lost jobs and means of livelihood, making them reluctant to spend on daughters' education, and inclined to let girls engage in income generating activities and household chores instead.

Shift to online education during COVID-19 induced lockdown proved difficult for girls and hindered their access to education, because girls in rural Rajasthan hardly own phones or computers and are dependent on use of phones belonging to their fathers, who are often otherwise engaged. Girls also found it difficult to understand online lessons, in absence of live interactions with teachers. As per study by Development Solutions and IDS Jaipur (2020), only 11\% girls could access online classes during the COVID lockdown.

\section{Building Girls’ Leadership: Pilot in Karauli, Rajasthan}

Given the context and status of education for young girls in Rajasthan and the added impact of COVID-19 limiting their access to education and safe spaces, Delhi-based international development consultancy IPE Global, and Rajasthan-based civil society organisation, Alwar Mewat Institute of Education and Development (AMIED), partnered to pilot a leadership model with 100 girls belonging to Scheduled Caste (SC), Scheduled Tribe (ST) and Other Backward Classes (OBCs) communities. The model is adapted from the pedagogy of leadership practice developed by Dr Marshall Ganz and colleagues, which integrates social movement experience with social science research. The leadership practice is structured into a programme, designed, and facilitated by the Harvard Kennedy School under Leadership, Organising and Action (LOA).

\section{Understanding the Pedagogy of LOA}

Social movements emerge as a result of the effort by individuals/ organisations to assert new public values, form new relationships and mobilise power to turn those values into action. Social movements are organised by identifying, recruiting, and developing leadership at all levels and the leadership accepts responsibility for the collective as a whole rather than at individual levels. Leading social movements requires having the desire for change but also the capacity to make change, managing core tensions, creating structure to create the space for growth, creativity and action, the ability to strategize and sustain motivation (Ganz and Lin, 2011). 
Dr Ganz and colleagues conceptualised social movement leadership as accepting responsibility for enabling others to achieve shared purpose (Ganz, 2010). It is a practice and not a position of formal authority and can be experientially learned by combining the "heart, head and hands" approach which in other words nurtures and supports the motivational, strategic and skill development of leaders (Ganz and McKenna, 2017). The framework is exercised through five interdependent practices (Ganz, 2010; Ganz and Lin, 2011):

Building Relationships: Social movements recruit individual participants by building relationships with them and goes beyond mobilising individuals and transaction of resources. An exchange becomes a relationship when there is a shared understanding, commitments, and collaborative action towards a shared future. Relational resources are core to a social movement, building new ones and nurturing the old, necessitates that leaders at all levels take responsibility. This requires training all leaders in one-to-one meetings, group meetings to grow and strengthen the movement.

Narrative: Stories are powerful as they translate our values into action and every movement has a story to tell, which is an important leadership practice. Stories articulate the motivational values of an individual, of a collective and the urgent need to act and link people with one another. Movement leadership develops narrative to access resources that are necessary to confront challenges with courage, resilience, and agency.

Strategy: Strategy is the practice of turning resources into power to get what you want and while narrative draws on one's emotional resources, strategizing draws on one's cognitive resources. It is rooted in the theory of change; it orients current action towards future goals while adapting to an everchanging environment. The strategic challenge for most social movement leaders is to successfully challenge those in power and here the story of David and Goliath becomes most useful for the movement strategist.

Structure: Social movement leadership requires not only adapting to the rhythm of change but also structuring the space such that leadership can grow. Structuring leadership practice away from the heroic individual to a team approach, where individuals would acquire skills and capacity that were inherently collaborative, and accountability and motivation was embedded in team membership.

Action: Resources like time, money and commitment need to be mobilised to a common effort and deployed through diverse tactics. It is the bottom line of the motivational, relational, and strategic work. Effective action requires getting commitments, turning strategy into measurable outcomes and specific deadlines, building leadership of others, designing motivational tasks for volunteers, and always having a contingency plan.

The five leadership practices were adopted and tweaked according to the context of Rajasthan to build the leadership of 100 girls over a period of 6 months in 2020-21. In several batches, the young girls went through a combination of virtual and on ground capacity building. As part of the leadership development, the 100 girls organised themselves as the "Movement for Dalit, Adivasi and Backward Classes Girls' Education." This movement followed a snowflake structure, with a core leadership team of 10 girls, each girl from the core team recruited and developed the leadership of 10 other girls resulting in 100 girl leaders. These girl leaders have further recruited and mobilised several other girls in their communities through one-one meetings, community meetings and meetings with families. The girl leaders have identified a shared purpose to ensure that every girl in Rajasthan, especially 
belonging to marginalised households, should have access to free and equitable education till the 12th grade. In this regard they have met with important political leaders across the State to voice their demands. They strengthened the movement by identifying and recruiting more girls to join and are recognised as a social movement in Rajasthan with 1240 girls participating and these numbers growing beyond Karauli to other districts.

\section{Research Objective}

In this paper, we have studied the role of Leadership, Organising and Action (LOA) in building girls' leadership from marginalised communities namely SCs, STs and OBCs and supporting them in exercising their voice and agency towards accessing education and bridging inequalities. Specifically, we wanted to understand the role of LOA in

- Building leadership skills of the girls to demand improved access to education,

- Creating value for completing education among girls, their family, and the community,

- Realising the power of collective in attaining common objectives and goals,

- Challenging the caste and gender discrimination girls face in their families, schools, and community while accessing education,

- Girl leaders becoming a social and political force in their district of Rajasthan, with enhanced agency and voice,

- Building the girls' knowledge / awareness and contribution to them exercising their voice and agency to demand equitable access to education.

\section{Methods}

The present research was carried out with girls in Karauli district of Rajasthan, the district where the leadership model based on LOA was piloted. The study was carried out using qualitative survey methods with girls who have been a part of the movement. Qualitative research methods were considered most appropriate as the nature of research is subjective and findings cannot be quantified.

We selected girls from among the 100 who joined the movement in the first phase of leadership building. These girls have received leadership trainings based on the LOA model and can apply the learnings in their movement building. We followed purposive sampling to select the girls for FGDs to ensure diversity in the villages they came from (to ensure regional diversity) as well as ensure representation from all three social groups - the SCs, STs and OBCs - among the study respondents. The girls included in the FGDs belonged to age groups 14-18 years and all the girls were enrolled in schools at the time of the study.

Post the selection of girls, structured, open-ended questionnaires were prepared by the researchers, based on the objectives of the study. The questionnaires developed were shared with three programme colleagues who were familiar with the LOA methodology and trainings given to the girls in the movement, for their feedback and review. The review received was incorporated and questionnaires were revised further. The questionnaires were then translated into Hindi language (local language in Rajasthan which the girls were more comfortable using) for the FGDs. 
Focused Group Discussions (FGDs) were conducted with these girls, during the month of April 2021. Each FGD was conducted with girls, in groups 6-7 girls each. The FGDs were conducted online through video calls due to COVID-induced lockdown and related restrictions on the movement of people within the state. Rajasthan-based NGO, AMIED, helped in mobilising the girls and facilitate the logistical and technological requirements for conducting these FGDs. The FGDs were conducted in complete privacy with girls and AMIED staff were not a part of these FGDs. Informed consent of the girls and their parents was taken before conducting the FGDs, informing them about the purpose of the study, how the discussions would be used by researchers and commitment to maintain their privacy and confidentiality.

The optimum number of FGDs was arrived at using the principle of thematic saturation, or redundancy of additional information. Ideally, new information is collected till saturation or a point at which little or no new information is gained with each additional discussion (Lincoln and Guba, 1986). We conducted five FGDs with the girls for the study, after which no new insights were being shared across the different research themes.

The FGDs were conducted by two researchers i.e., where one conducted the discussion with the girls and the other researcher took down the notes. The discussions were recorded with consent of the participating girls to capture the discussion. Post the FGDs, transcription of the FGDs was done with help of the recordings and the written notes of the researchers. The transcripts were translated into English (from Hindi language) and detailed notes were prepared for analysis.

Seven themes were identified for the analysis in line with LOA pedagogy, which include: (1) Challenges that girls faced which made them want to be leaders; (2) Building relationships; (3) Narrative of the collective; (4) Change which girls would like to see and how will they achieve it; (5) Current structure of the movement; (6) Activities undertaken; and (7) Outcomes. Scissor and Sort technique was used to identify and sort the transcript as per the different themes. The sorted transcripts were then analysed in detailed, in context of the seven themes, and insights and analysis were drawn. These were mapped against the study's research objectives to draw conclusions on our research questions.

The findings from the FGDs were also corroborated with AMIED's documentation of activities on ground by the girls. Records of the on-ground activities, meetings with political leaders, instances of child marriages averted etc. were studied in-depth by the researchers using documented case studies, social media handles of the girls' movement, photographs and video recordings and other sources of information available.

The conclusions drawn from the analysis have been presented in the Results section below.

\section{Results}

The results are presented based on the identified themes for analysis and later discussed in context of the research objectives.

(1) Challenges faced by the girls which made them want to be leaders: The girls shared several challenges especially during the lockdown which was put in place to contain the spread of the disease. A major challenge was the economic hardships their families faced due to loss of livelihoods, which 
made it difficult for them to spend money on girls' education amidst limited resources and fight for survival. The fact that girls' education at secondary level is not free, made it even more difficult for the families to support their education. Several families planned to marry their under-age daughters during this time. Girls' access to education was further restricted due to closure of schools, and a shift to online mediums of teaching. None of the girls had their own phones or access to a computer to access these online classes, which severely impacted their studies. The situation was made more difficult due to lack of incentives such as any scholarships to support girls' education. The girls wanted to join the movement and become leaders as they believed the movement is for their rights. Through the movement they want to ensure that every girl in Rajasthan studies till at least $12^{\text {th }}$ grade (i.e., till age of 18 years, the legal age of marriage for girls in India). The girls believed that scholarships could support their education by easing the economic burden on their families.

(2) Building relationships: Relationship building, which is one of the initial steps of the LOA model, proved to be effective for girl leaders, who initially found this challenging. They shared that the families of the girls who wanted to join the movement were reluctant to let their daughters participate. They were highly suspicious of the objective and what will their daughters learn if they participated. However, repeated meetings with the girls' parents and explaining the purpose of the movement, helped gradually change their minds and permitted the girls join. The girls, on the other hand, wanted to join the movement and believed that the movement would help them attain their objectives and shared vision that all girls in Rajasthan should study at least till the $12^{\text {th }}$ grade and no girl should be forced to marry before the legal age of marriage.

(3) Narrative of the collective: For the girls, the story of the movement began with their own experiences of facing gender and caste discrimination. All the girls who took part in the study had faced some form of gender or / and caste discrimination; they also saw these practices every day in their families, schools, community, and society. They shared that being a girl and belonging to a certain caste made them victims of discrimination and they felt that they were not treated as humans and felt afraid. Most believed that this is the way things are supposed to be. It was after joining the movement they felt that everyone is equal and needs to be treated the same, and with respect.

They also shared the story of their movement that was started by ten girls during the COVID-19 lockdown and today has a strength of over 1200 girls. The girls feel that the movement gives them strength and courage to challenge the discriminatory norms on gender and caste, within their families as well as the society. Each girl we spoke to, had joined the movement as a thought-out decision arising from a need to bring about change. This movement has made them aware of their rights, built their identity and brought about a positive change in their lives.

(4) Change which girls would like to see and how will they achieve it: The girls share a common vision of the changes they want to see through their movement in the state of Rajasthan. They would like all girls in Rajasthan to study till at least $12^{\text {th }}$ grade, and that no girl is married before the legal age. They want scholarships to promote girls' education at the secondary and higher secondary levels to incentivise the parents to send their daughters to school and help meet the education expenses. They feel that the present scholarship amount given by the Government of Rajasthan is less and should be enhanced. The girls demand that there should be no child labour and all girls should have the opportunity to study further. They believe that all girls should be aware of their rights and should 
stand up for the same and homes, society should be equitable places with no gender or caste discrimination.

These changes can be achieved by expanding their movement to the entire state of Rajasthan and involving more girls. They feel that if they can take their demands to the people who matter in the state i.e., policymakers and the government, including the Chief Minister of the state, then their demands can be met. These changes with respect to both gender and caste discrimination require a larger change in the mindset of their families, community, and the society. For this they will also have to engage with a range of stakeholders like the village heads, frontline workers, teachers, among others, because the need is to change everyone's mindset, changing one person's mindset will not change the society.

(5) Current structure of the movement: The girls shared the story of how the movement had started during the COVID-lockdown by ten girls who wanted to fight for girls' right to be educated. These girls came together and recruited two girls each in 50 villages of Karauli district, making it a collective of 100 leader girls. These leader girls received leadership trainings during this initial phase. Each of these 100 girls in turn mobilised 10-15 girls each in their respective villages, making it a movement of over 1240 girls in Karauli at present. They aim to take the movement beyond Karauli and are in process of mobilising more girls in other districts of Rajasthan, through support of local civil society organisations in those districts.

Presently the movement has ten cluster coordinators in place looking after five villages each. They are supported by two leader girls in each of the 50 villages, i.e., the 100 girl leaders.

(6) Activities undertaken: The girls undertook several activities to spread their messages and build awareness around their issues and demands at the village, district, and state levels. An important activity was conducting one-to-one meetings and community meetings with the community to get more girls join the movement and garner support for their demands. To popularise their messages and issues, they conducted street plays, wrote slogans, did wall paintings in villages, and took out village rallies. They submitted memorandums to the village heads in their respective villages with the issues they face in accessing education and their demands from village leadership to address some of these issues. They convened at the district and then at state level for workshops and meetings with other girls as well as key stakeholders to spread their demands and make their voices heard. A delegation of the girls met with the State Education Minister - Mr Govind Singh Dotasara and State Labour Minister - Mr Tikaram Julie to put across their issues and asks, demanding action on an urgent basis. The girls also submitted their demands before the Chief Minister of the State - Mr Ashok Gehlot, who extended support for their movement and opened avenues for further engagement.

(7) Outcomes: The movement has resulted in a positive change in the lives of the girl leaders, and they see a reflection of this in their society as well. The biggest change the girls see is in themselves. They were earlier afraid to raise their concerns at home, are now able to fearlessly raise their demands. They feel that their mobility has increased; they are allowed to go outside their homes, go around the villages, travel outside the district, something they could not do earlier. All the girls believe that now they will be able to complete their education till at least $12^{\text {th }}$ grade, which would not have happened if they had not been part of the movement. In fact, they share that "if they were not 
associated with the collective, that many would have been married by now". The movement has been instrumental in enhancing their agency and empowering them.

There has also been a change in mindset of their families, but this change is limited. For example, girls are sure that their parents would let them study till $12^{\text {th }}$ grade, something they were not in favour of earlier. But if the girls want to study beyond, or travel outside the district to study or for jobs, their parents will not agree readily for the same and will need a lot of convincing.

The change in societal attitude has also been positive but limited. There has been some headway on addressing caste discrimination and girls shared that now they see people from different castes mingling together, sitting together and even drinking water from same tap. Girls, themselves, have also started fighting caste-based discrimination among themselves and seeing everyone as equal. However, these changes are limited and the larger societal shift on both gender and caste discrimination will take a long time. Girls are of the opinion that since gender and caste discrimination have been practiced for many decades, any change in either will be a slow process. But they are hopeful this change will come eventually.

The movement's key demand has been to enhance the scholarship amount and ensure that all girls in Rajasthan get scholarship at secondary and higher secondary levels. This demand has not been met till now and girls feel that more work is required for the same.

The girls want to take the movement further and feel that parents and siblings should also be involved in the movement, so ensure a positive change in their families as well as the society. They also feel that the movement should continue so that other girls in the state, including younger girls, can also benefit from the movement.

\section{Discussion}

The LOA pedagogy which is based on the leadership practices developed by Dr Ganz and colleagues for social movement leadership, was successful in building the leadership of girls in the Karauli district of Rajasthan. They organised themselves under the "Movement for Dalit, Adivasi and Backward Classes Girls' Education", and all girls identify themselves as leaders. This shift in identity from oppressed to leadership is an important milestone as it built their confidence and courage to voice concerns and raise their demands not only among themselves but also the larger community, in an extremely patriarchal context.

As a movement, girl leaders were able to appreciate the need for a shared purpose $\&$ shared goals, which is to ensure that every girl in Rajasthan should have access to free and equitable education till at least the $12^{\text {th }}$ grade. The act of organising and forming a collective towards a shared purpose was a reflection of their values and rooted in fighting gender and caste-based discrimination and the need for an equal society. The girl leaders expressed their values through their own stories and lived experiences, stating their challenges in accessing secondary and higher education, the discrimination they experienced at the household and community level and shared their hope for a more equal future.

One of the key leadership practices is relationship building which the girls exercised well in growing and strengthening the movement. They built relationships with each other in group meetings and oneone meetings which helped them build trust and arrive at a shared purpose. Relationship building was 
very important in convincing the families to permit the girls to be part of this movement and attend the trainings. As expressed by the girls, being part of the movement was a well-thought-out decision as they strongly believed that this was for them, and their rights and they derived courage from this collective. There was an understanding that the changes they have seen within themselves, and their families would not have been possible at an individual level and organising was necessary.

The movement has a core leadership team of ten girls which drives decision-making within the movement on planning key activities. The movement is structured in a snowflake model with each core girl leader recruiting and training two more girl leaders who in turn mobilise 10-15 girls in their villages. But despite this structure, the role of distributed leadership responsibility is not yet realised by the other girls. Apart from structured leadership, the girls are yet to start strategizing on their own that leads to effective action and currently girls plan and implement tactics not always backed by strategy. Both structure and strategy, key practices under the LOA, will require more experiential training and time with the girl leaders. As the girl leaders have expressed, their movement requires more work as their demands on increasing Government scholarships and access to free and equitable education for girls has not been achieved as yet.

Some key successes of girls organising using the LOA has been developing an understanding of caste and gender-based discrimination and challenging it through their work. They understand that this oppression is deep rooted in their society and will not change overnight, but they are willing to continue the struggle as it will benefit the future generations. Girl leaders are able to exercise their voice and agency to demand their right to access secondary and higher education, which was not possible prior to the movement. The leadership development made visible changes in the lives of girls as some of them mentioned that the presence of a visible movement was able to avert child marriages in their communities. The girl leaders have been featured in regional media because the work that they have been doing in Karauli, making the movement a visible social force in the State, further increasing their confidence. Overall, the girls enjoy greater agency and voice, and they are no longer fear raising their demands with stakeholders including key decision makers in the State.

This pilot has seen significant success towards adapting an international leadership practice in the local context of Karauli district in Rajasthan state, with several elements of the LOA pedagogy working well in the girls' movement. This builds a strong case for replicating the leadership model in other districts, and scaling-up the practice across the state of Rajasthan. While there is scope for improvement in the present structure of the girls' movement and strengthening some elements of the LOA pedagogy (such as strengthening distributed leadership), measures can be taken to give special focus on such elements while replicating in other districts. The lessons learnt from the pilot in Karauli will be critical in informing its replication. Rajasthan, a largely patriarchal state, can benefit greatly from girls' leadership for positive change on gender and caste discrimination, and become an example for other states in the country to follow.

The present study was carried out amidst severe restrictions during the COVID-induced lockdowns, restricting the scope of the research significantly. For example, while in-depth personal interviews had also been planned with the girls, their parents, and other relevant stakeholders, such as village-level frontline workers, village heads, political leadership, etc. these could not be completed due to restrictions on mobility and the people grappling with a severe health crisis across amidst the second wave of COVID in India. There is, however, scope to strengthen the study further by including more 
and diverse respondents for the study to build a more holistic understanding. With a sufficiently large study sample, there is also scope for further analysis such as applicability of findings for different caste-groups, across different districts representing different social settings and governance systems, among others.

\section{Conclusion}

Based on the findings of our study, the LOA pedagogy for building leadership of adolescent girls in Rajasthan has been successful in advocating for their rights for equitable education. There has been a visible increase in their agency, ability to understand organising for change and shifting power to achieve their objectives. The girl leaders are also better equipped to articulate a shared vision for their movement, which has become a visible social force in the State within a year. This model becomes exceptionally relevant, to build leadership of girls in regions which are feudal with rampant discrimination that limits access to basic rights granted to them under the Constitution of India. While the movement is relatively new and there is still some learning and training required on certain aspects of the LOA pedagogy, it is unique as girls under the age of 20 are not only leading this movement but publicly challenging age-old social norms of patriarchy and casteism which is deep rooted in a state like Rajasthan. We would recommend that the pilot in Karauli, Rajasthan, be scaled to other districts such that there are more girl leaders emerging from the most disadvantaged communities, bridging the substantial gender and caste gap in education in the State.

\section{Acknowledgements}

Authors would like to extend their gratitude to Mr Noor Mohammad, Ms Sangeeta Dadhich, Ms Neha Sethi and Ms Salonie Chawla for their invaluable support and inputs throughout the work on the girls' alliance building as well as during the course of writing this paper. We would also like to thank the team at AMIED for helping us during the study, especially with the logistical support for conducting the FGDs. And last but not the least, we would like to thank all the girl leaders whose passion and drive to bring about a change has been an inspiration for us and this paper. Errors or omissions, if any, are solely our own.

\section{Declaration of Interest Statement}

The authors declare that they have no conflict of interests.

\section{References}

Awasthy , G. \& Khimani, V. (2015). Academic challenges Faced By First Generation Learners In An NGO-Run School vis-à-vis Government School in the Nainital District (Uttarakhand) of North India. Azim Premji University. Retrieved from: http:azimpremjiuniversity.edu.in/Sitepages /pdf/Garima Varun Itr\%20Report.pdf

Bhagavatheeswarana, L.; Nair, B.; Stonea, H.; Isaac, S.; Hiremath, T.; Raghavendra, T. et al. (2016). The Barriers and Enablers to Education Among Scheduled Caste and Scheduled Tribe Adolescent Girls in Northern Karnataka, South India: A Qualitative Study. International Journal of Educational Development, Volume 49 (2016), pp. 262-270. DOI http://dx.doi.org/10.1016/j.ijedudev.2016.04.004 
Choudhary, H. (2019). Girl Child Education in Rural Rajasthan. PEOPLE: International Journal of Social Sciences, ISSN 2454-5899; Volume 5 (Issue 2), pp. 893-907. DOIhttps://dx.doi.org/10.20319/pijss.2019.52.893907

Development Solutions and IDS Jaipur (2020). Perception Survey to Understand Barriers and Enablers to Girls' Secondary Education in Rajasthan in the context of COVID-19. Retrieved from: https://www.devsolutions.org/wp-content/uploads/2020/12/Study-report_Perception-Survey_DS.pdf

Ellis-Petersen, H. (2020, October 1). Covid crisis could force extra $2.5 \mathrm{~m}$ girls into child marriage charity. The Guardian, Retrieved from: https://www.theguardian.com/society/2020/oct/01/covidcrisis-could-force-extra-25m-girls-into-child-marriage-charity

Ganz, M. (2010). Leading Change: Leadership, Organisation and Social Movements. In Handbook of Leadership Theory and Practice. Harvard Business School Publishing Corporation.

Ganz, M. \& Lin, E. (2011). Learning to Lead: Pedagogy of Practice. In S. Snook; N. Nohria; \& R. Khurana (Eds.), Handbook for Teaching Leadership: Knowing, Doing, and Being (pp. 353-366). SAGE Publications.

Ganz, M. \& McKenna, L. (2017). The Practice of Social Movement Leadership. Mobilising Ideas.

Ghosh, S. (2014). The Silent Exclusion of First Generation Learners from Educational Scenario-A Profile From Puncha Block Of Purulia District, West Bengal. International Journal of Developmental Research, pp. 804-811.

Indian Institute of Population Studies. (2017). Rajasthan State Report: National Family Health Survey-4, Indian Institute of Population Studies.

Jejeebhoy. S. J. \& Acharya, R. (2014). Adolescents in Rajasthan 2012: Changing Situation and Needs. Population Council.

Lincoln, Y. S., \& Guba, E. G. (1986). But is it rigorous? Trustworthiness and Authenticity in Naturalistic Evaluation. New Directions for Program Evaluation, Volume 30 (1986), pp. 73-84

Ministry of Human Resource Development. (2018). Educational Statistics at A Glance 2018. Government of India.

Nagpal, N. (n.d.). Report on Field Study in Rajasthan State -Situational Analysis of field conditions with respect to the proposed interventions in Rajasthan State under TATA -MIT Education Initiative. Centre for Education Research and Practice (CERP)

Nambissan, G. (2009). Exclusion and Discrimination in Schools: Experiences of Dalit Children. Indian Institute of Dalit Studies and UNICEF.

National Sample Survey Organisation. (2018). NSS Report No. 585: Household Social Consumption on Education in India, July 2017-June 2018. Ministry of Statistics and Planning, Government of India.

National University of Educational Planning and Administration (various years). Elementary Education in India - Where Do We Stand? State Report Cards. Government of India. Retrieved from: http://udise.in/src.htm

Parth M.N. (2021, June 9). India's marginalised girls fighting child marriage. Aljazeera, Retrieved from: https://www.aljazeera.com/news/2021/6/9/girls-india-marginalised-groups-child-marriage

Registrar General of India (2011). Census of India 2011, Ministry of Home Affairs, Government of India 